\title{
Effects of nicotine administration in rats on MMP2 and VEGF levels in periodontal membrane
}

\author{
B. Deveci ${ }^{1}$, B. Ayna ${ }^{2}$, i.H. Tacir ${ }^{3}$, E. Deveci ${ }^{4}$, M.C. Tuncer ${ }^{5}$, A. Pala ${ }^{4}$ \\ ${ }^{1}$ Department of Periodontology, Faculty of Dentistry, University of Dicle, Diyarbakir, Turkey \\ ${ }^{2}$ Department of Paediatric Dentistry, Faculty of Dentistry, University of Dicle, Diyarbakir, Turkey \\ ${ }^{3}$ Department of Prosthodontics, Faculty of Dentistry, University of Dicle, Diyarbakir, Turkey \\ ${ }^{4}$ Department of Histology and Embryology, Faculty of Medicine, University of Dicle, Diyarbakir, Turkey \\ ${ }^{5}$ Department of Anatomy, Faculty of Medicine, University of Dicle, Diyarbakir, Turkey
}

[Received: 18 December 2017; Accepted: 27 December 2017]

\begin{abstract}
Background: Nicotine is associated with increased incidence of periodontal disease and poor response to therapy. This article aimed at identifying the expression of matrix metalloproteinases 2 (MMPs2) and vascular endothelial growth factor (VEGF) proteins on extracellular matrix, fibrous distribution and angiogenetic development in periodontitis caused by nicotine effects on periodontal membrane. Materials and methods: In this experimental study, rats were divided into nicotine and control groups. While the rats in the nicotine group $(n=6)$ were administered $2 \mathrm{mg} / \mathrm{kg}$ nicotine sulphate for 28 days, the animals in the control group $(n=6)$ were only administered $1.5 \mathrm{~mL}$ physiologic saline solution subcutaneously for 28 days.

Results: Histological sections were prepared and immunohistochemically stained for MMP2 and VEGF. The sections stained with Trichrome-Masson were observed under light microscope. VEGF and MMP2 immunoreactivity of periodontal gingiva and dentin was assessed by immunohistochemical staining.

Conclusions: Nicotine reduces MMP production, disrupts collagen synthesis and causes periodontitis. We observed that nicotine increases periodontitis by disrupting periodontal membrane and prevents tooth to anchor in dental alveoli by disrupting epithelial structure. (Folia Morphol 2018; 77, 3: 471-477)
\end{abstract}

Key words: MMP2, VEGF, periodontal membrane, rat, immunohistochemistry, nicotine

\section{INTRODUCTION}

Periodontal disease is one of the major dental pathologies that affect human populations worldwide at high prevalence rates. Periodontitis is a multifactorial disease that involves microbial challenge and host responses. Although bacteria are the initial factors for human periodontitis, their impact may be modified by an individual's predisposition, which can determine the manifestation and progression of the disease [11]. Matrix metalloproteinases (MMPs) play an important role in physiological and pathological events, including the repair and breakdown of connective tissue because of the inflammatory response [20]. Excessive production of MMP2 because of genetic polymorphisms may influence the manifestation and development of periodontal diseases [28]. The underlying mechanisms causing these pathological conditions are still unclear. Two mechanisms were

Address for correspondence: Prof. M.C. Tuncer, PhD, Department of Anatomy, Faculty of Medicine, Dicle University, Diyarbakır, Turkey, tel: +90 412 2488001, ext. 4539 (Faculty room), fax: +90 532 2744926, e-mail: drcudi@hotmail.com 
proposed to explain this progression: bacteria acquire the ability to penetrate the deeper tissues [16], and/or the host response is degraded [3]. In particular, resident periodontal ligament and gingival fibroblasts have been reported to secrete MMPs and chemoattractants for epithelial cells [14]. Different proteoglycans and glycosaminoglycans, such as syndecan 1 , also seem to play an important role in the inflammation during periodontal disease $[1,25]$. The progression of inflammation and periodontal destruction requires a response to a bacterial insult; that includes resident cells that sustain signals to trigger the immune response. Host-derived cytokines released upon microbial challenge have significant effects on the immune and inflammatory responses in periodontal disease [12, 37].

Previous studies have demonstrated that daily injection of nicotine causes significantly heavier alveolar part resorption in rats than injection of saline $[8,30]$. Compared with non-smoking periodontitis, the height and density of alveolar part in the periodontal tissue of smoking-associated periodontitis is lower, and closely related to smoking dose and time [29]. MMP2 plays a pivotal role in remodelling basement membranes via pericellular and cell-attachment proteins $[33,36,41]$. Vascular endothelial growth factor (VEGF) has been reported to stimulate endothelial cell proliferation, which plays a key role in the regulation of physiological and pathological angiogenesis, thereby affecting angiogenesis and increasing vascular permeability [24]. This protein seems to be involved in the onset and progression of gingivitis and periodontitis, mainly by promoting the vascular network expansion generally observed in inflammation [22]. Studies intended to associate the action of VEGF with the pathogens of periodontal disease have reported controversial findings. Nevertheless, VEGF expression is more strongly related to the healing stage of periodontal disease than to the destruction stage of the lesion [10].

The purpose of this study is to investigate the effects of MMP2 and VEGF proteins on extracellular matrix, fibrous distribution and angiogenetic development in periodontitis caused by nicotine effect on periodontal membrane and alveolar part of mandible.

\section{MATERIALS AND METHODS}

\section{Animals and experimental design}

All procedures performed in this experiment were approved by the Ethics Committee for the Treatment of Experimental Animals (Faculty of Medicine, University of
Dicle, Turkey). Twelve Wistar male rats (180-250 g) were maintained under $22 \pm 1^{\circ} \mathrm{C}$ and $12 \mathrm{~h} \mathrm{light/dark}$ cycles with ad libitum access to standard pelleted food and water. The rats were divided into two groups: nicotine group and control group. The rats of the nicotine group $(n=6)$ were nicotinised systemically with nicotine sulphate (Sigma, Aldrich), $2 \mathrm{mg} / \mathrm{kg}$ subcutaneously, daily for 28 days. The rats of the control group $(n=6)$ were used as control and only administered $1.5 \mathrm{~mL}$ physiologic saline solution subcutaneously for 28 days. The rats of the control group were maintained in same environment and food as the experimental group. All rats at the end of experiment were healthy and no difference in food/water consumption and body weight gain between experimental and control rats were observed. At the end of the study, the animals were sacrificed using a decapitator (Harvard Apparatus, Holliston, MA, USA). The body of mandible (alveolar part) was dissected under ketamine hydrochloride anaesthesia. Alveolar part (pars alveolaris) was removed with molar tooth backward from the lower incisor tooth. The samples were fixed with neutral buffered $10 \%$ formalin solution and decalcified with $5 \%$ ethylenediaminetetraacetic acid (EDTA). After preservation, alveolar part samples were directly dehydrated in a graded series of ethanol and embedded into paraffin wax. Five $\mathrm{mm}$ sections were cut with microtome (Rotatory Microtome, Leica, RM 2265, Germany) and mounted on the coated slides. The sections were stained with Trichrome-Masson in order to be observed under light microscope.

\section{Immunohistochemical staining}

Antigen retrieval process was performed in citrate buffer solution (pH: 6.0) two times: boiled in microwave oven at $700 \mathrm{~W}$ first for $6 \mathrm{~min}$, and then for $4 \mathrm{~min}$. They were allowed to cool to room temperature for $20 \mathrm{~min}$ and washed two times in distilled water for $4 \mathrm{~min}$. Endogenous peroxidase activity was blocked in $0.1 \%$ hydrogen peroxide for $10 \mathrm{~min}$. Ultra $\mathrm{V}$ block (Histostain-Plus Kit, Invitrogen, Carlsbad, CA) was applied for $8 \mathrm{~min}$ prior to the application of primary antibodies: MMP2 antibody, mouse monoclonal, 1/100, Santa Cruz and VEGF antibody, mouse monoclonal, $1 / 100$, Santa Cruz for overnight. Secondary antibody (Histostain-Plus Kit, Invitrogen, Carlsbad, CA) was applied for $20 \mathrm{~min}$. Then, slides were exposed to streptavidin-peroxidase for $25 \mathrm{~min}$. Diaminobenzidine (DAB, Invitrogen, Carlsbad) was used as a chromogen. Control slides were prepared as mentioned above but 
Table 1. Comparison of nicotine and control groups in terms of matrix metalloproteinases 2 (MMPs2) and vascular endothelial growth factor (VEGF) expression and histopathological features

\begin{tabular}{lccc}
\hline & $\begin{array}{c}\text { Control }(\mathbf{n}=\mathbf{6}) \\
\text { (mean } \pm \text { standard deviation) }\end{array}$ & $\begin{array}{c}\text { Nicotine }(\mathbf{n}=\mathbf{6}) \\
\text { (mean } \pm \text { standard deviation) }\end{array}$ & $\mathbf{P}$ \\
\hline Dilatation and haemorrhage in blood vessels & $0.01 \pm 0.03$ & $4.0 \pm 0.0$ & $\leq 0.001$ \\
Mononuclear cells infiltration & $0.23 \pm 0.41$ & $2.63 \pm 0.20$ & $<0.01$ \\
Damage of collagen fibres & $0.0 \pm 0.0$ & $1.80 \pm 0.20$ & $\leq 0.001$ \\
VEGF expression & $1.53 \pm 0.5$ & $4.53 \pm 0.61$ & $<0.001$ \\
MMP2 expression & $3.62 \pm 0.3$ & $0.82 \pm 0.4$ & $<0.01$ \\
\hline
\end{tabular}
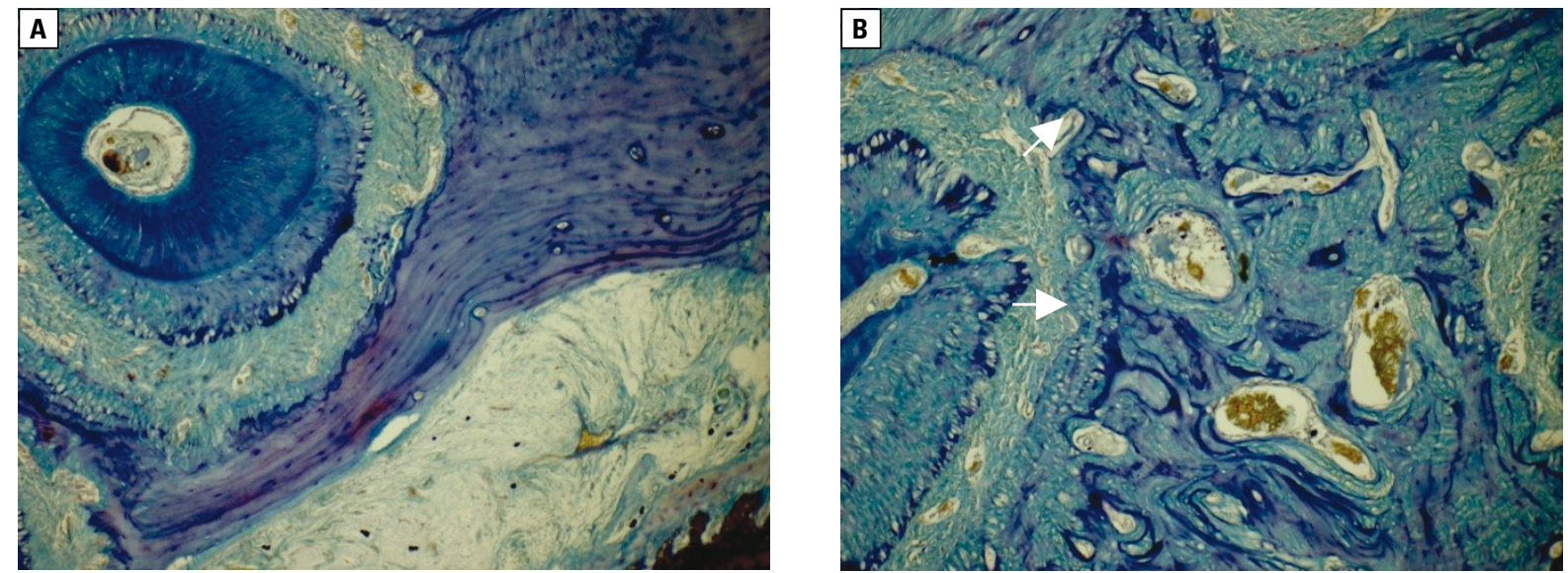

Figure 1. A. Control group: regular distribution of fibroblasts in collagen fibres. Trichrom Masson, bar $100 \mu \mathrm{m}$; B. Nicotine group: dilatation and haemorrhage in blood vessel (arrow), mononuclear cell infiltration around vessels, hyperplasia in fibroblast cells, an increase in inflammatory cells between alveolar part of mandible and periodontal membrane (arrow), Trichrom Masson, bar $50 \mu \mathrm{m}$,

omitting the primary antibodies. After counterstaining with haematoxylin, washing in tap water for $4 \mathrm{~min}$ and in distilled water for $2 \times 4 \mathrm{~min}$, the slides were mounted.

\section{Statistical analysis}

Statistical analysis was performed with the Statistical Package for the Social Sciences for Windows (version 15.0, SPSS Inc., Chicago, IL, USA). The MannWhitney $\mathrm{U}$ test was used for the statistics as indicated. The results were expressed as mean \pm standard deviation. $P$ values below 0.05 were considered to indicate statistical significant.

\section{RESULTS}

The histopathological results of the present study were evaluated under light microscope. There were no histopathological changes in control group. We compared periodontal membrane and alveolar part of mandible between control and nicotine groups (Table 1).
Collagen fibres were parallelly dispersed throughout alveolar part of mandible, fibroblasts were in fusiform shape and their nuclei were centrally located. Dilated blood vessels and haemorrhage, mononuclear cell infiltration around vessels, hyperplasic fibroblast cells, increased number of inflammatory cells between alveolar part of mandible and periodontal membrane were observed in nicotine group. In the control group, there were no histological changes in the vascular endothelial cells and connective tissue of junction in where periodontal gingiva and alveolar part intersect. Positive VEGF expression was observed. In the nicotine group, elevated VEGF expression was observed in the endothelial cells of dilated vessels. In addition, inflammatory cells around collagen fibres showed increased VEGF expression. In the control group, MMP2 was also expressed in collagen fibres of periodontal gingiva and dentin, and tissue of alveolar part of mandible. In the nicotine group, MMP2 expression was weak in alveolar part and collagen fibres of tooth root region while it was strong in inflamed 

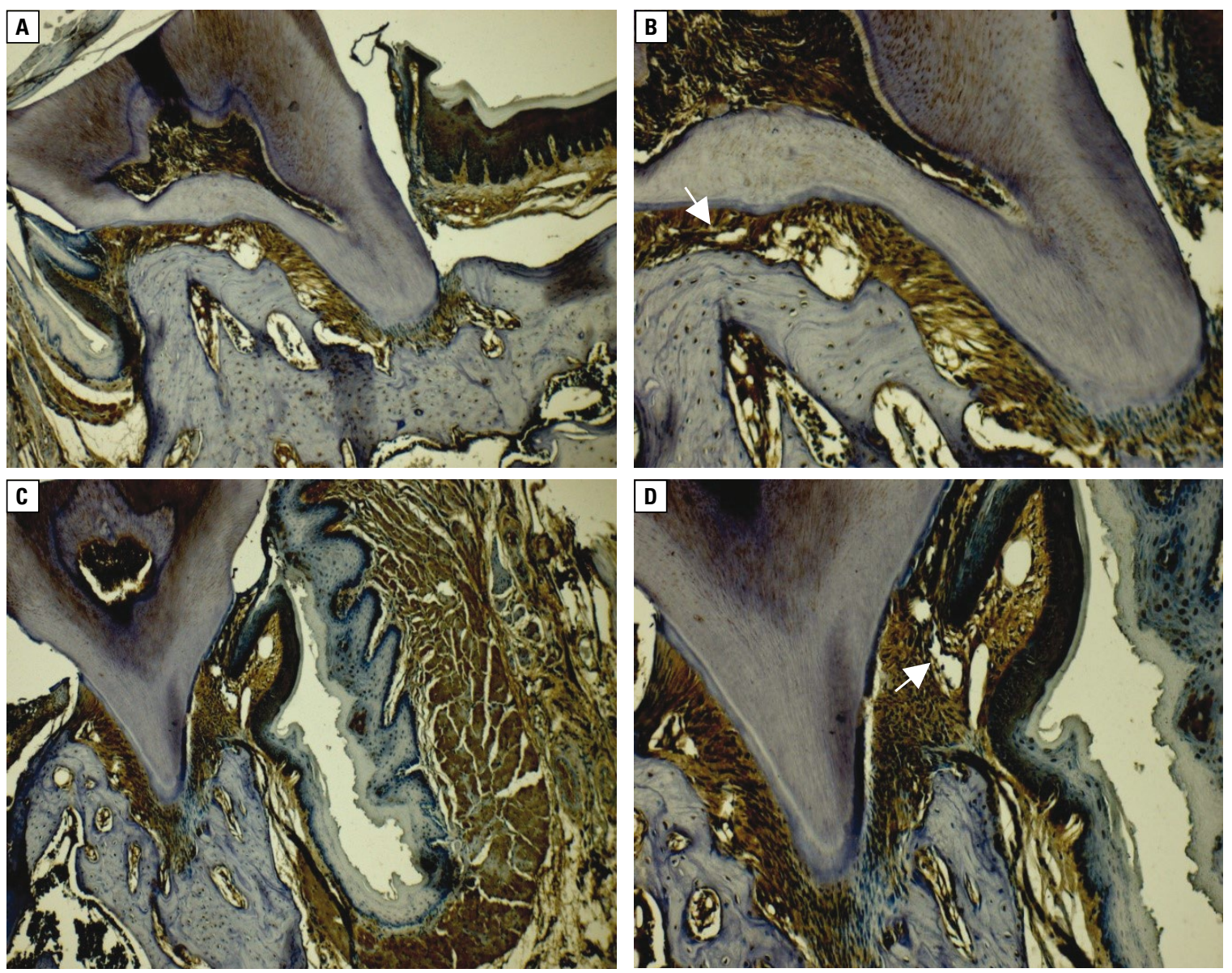

Figure 2. A, B. Control group: positive vascular endothelial growth factor (VEGF) expression in vascular endothelial cells in the gingival, periodontal membrane and alveolar junction (arrow), VEGF immune staining; bar $100 \mu \mathrm{m}$; C, D. Nicotine group: an increase in positive VEGF expression in vascular endothelial cells and inflammatory cells (arrow), VEGF immune staining; bar $50 \mu \mathrm{m}$.

cells. MMP2 expression was particularly positive in basal membrane of blood vessels (Figs. 1-3).

\section{DISCUSSION}

Periodontal disease encompassing both gingivitis and periodontitis is a host-mediated inflammatory process initiated by oral bacterial insult, which may result in significant alterations in the normal structure and/or function of the supporting tissues of the dentition. Although colonisation of host tissues by pathogenic organisms is the initiating factor in this disease process, the associated rate of progression and degree of destruction are dependent upon both the virulence of the invading organisms and the magnitude/persistence of the host response. Treatment of periodontal diseases has a great deal in common with the treatment of infectious diseases elsewhere in the body by controlling the putative pathogens. The goal of periodontal therapy is the elimination or reduction of periodontal pathogens from the oral cavity and the subgingival area response to this infection. And, one of the important factors is tobacco smoking, which is associated with aggravated periodontal tissue destruction, pocket formation, alveolar part (the body of mandible or maxilla) resorption in periodontitis $[5,18,21,39,40]$.

Pathogenic pathways involved in the imbalance of connective tissue homeostasis in periodontal inflammatory diseases are complex, and specific mediation is not completely understood. Activation of MMPs is one of the most important evolving under a rigorous control. MMPs are zinc-dependent proteases that break down extracellular matrix molecules, including dermal collagen and elastin. The proteolytic activity of MMPs has been reported to be inhibited by tissue inhibitors of metalloproteinases [23]. Nicotine has been reported to up-regulate MMP-1, MMP-2 and MMP-3 gene expression in arterial smooth muscle cells [9]. Cigarette smoke condensate has been reported to up-regulate MMP-1, MMP-8 and MMP-9 

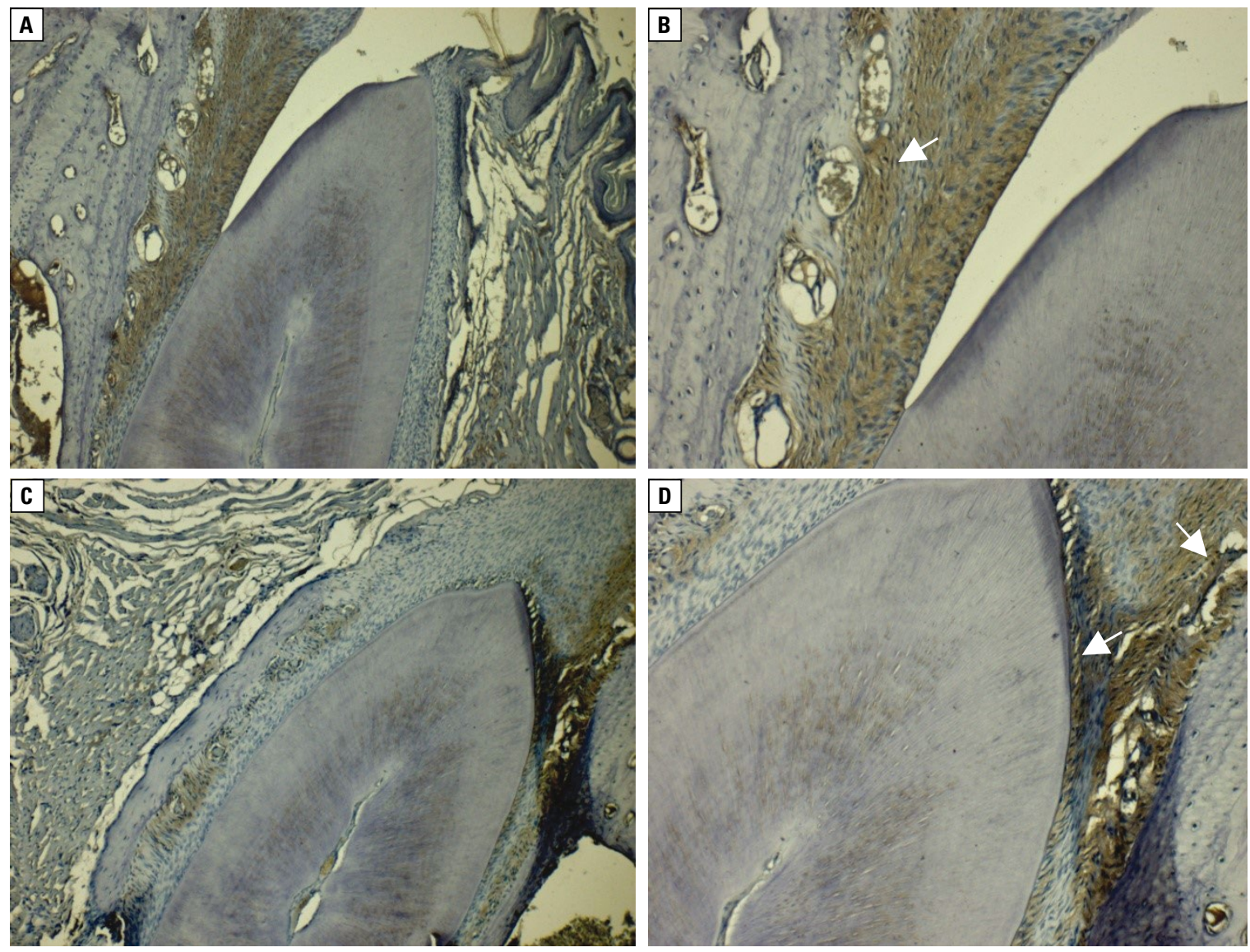

Figure 3. A, B. Control group: matrix metalloproteinase 2 (MMP2) expression at periodontal gingiva, and alveolar bone inter-sections, MMP2 immune staining; bar $100 \mu \mathrm{m}$; C, D. Nicotine group: MMP2 expression in collagen fibres is weak in dental alveoli, alveolar part of mandible and collagen fibres in periodontal membrane, MMP2 expression is positive in basal membranes of blood vessels (red arrow), MMP2 immune staining; bar $100 \mu \mathrm{m}$.

gene expression in vascular endothelial cells [34]. Faruk et al. [13] found that fibroblast metabolism could be altered by nicotine action and intercellular matrix synthesis was affected. It also affects periodontal ligament fibroblasts and stimulates osteoclasts activity $[19,42]$. In our study, nicotine administration caused a change in fibroblast activity due to the change of collagen fibre synthesis and decreased MMP2 expression. Several MMPs have been identified in the inflamed gingival tissues: MMP-1, $-2,-3,-8,-9$, -13 , produced by the keratinocytes, macrophages, polymorphonuclear leukocytes $[2,3,6,26,27]$. Their activity could be different depending on the severity of disease and the needs for extracellular matrix digestion. In some cases, MMP-1 expression extended to the lamina propria as inflammation progressed. Increased activity of MMP-1 could explain the change of collagen quality and quantity, since its preferred substrates are the type I and type III collagens. Several other researchers reported an intense collagenolytic activity of MMP-1 in fibroblasts and macrophages resident in the periodontal tissue $[4,26]$ and focused on the interrelation between MMP- 1 and MMP-3 in amplifying the proteolysis in chronic periodontitis [4].

The balance between MMPs and tissue inhibitors of metalloproteinases influence on extracellular matrix homeostasis in different types of tissues is tightly controlled by growth factors, a class of polypeptide hormones. One of the most important growth factors is VEGF. Over the last two decades researchers have demonstrated that VEGF is a key regulator of physiological and pathological angiogenesis, because it induces endothelial cell proliferation, stimulates angiogenesis and increases vascular permeability. VEGF immunoreactivity was observed in vascular endothelial cells, osteoblasts, osteoclasts in resorption lacunae, in fibroblasts adjacent to hyalinised tissue, a local necrotic area in compressed zone, and in mononuclear cells in periodontal tissues from the animals [32]. Growth factors mediate many events associated 
with turnover, repair and regeneration of periodontal tissues. Gingival epithelial cells, gingival fibroblasts, and periodontal ligament fibroblasts are the major cells involved in tissue repair. An appropriate response of these target cells to various growth factors depends on the expression of corresponding receptors. Studies have demonstrated inhibition of proliferation, extracellular matrix production, and attachment of human gingival fibroblast, in addition to increased collagenase activity in the presence of nicotine [38]. In periodontitis patients, VEGF was detected within vascular endothelial cells, neutrophils, plasma cells, and junctional, pocket and gingival epithelium [7]. In a previous study on biopsies obtained from patients with type 2 diabetes-associated gingival overgrowth, we detected VEGF expression in keratinocytes from the basal and spinous layers and in many de novo capillaries [35]. Other authors reported increased VEGF expression in epithelial cells and endothelial cells in periodontitis-affected gingiva [17, 24, 31]. Giannobile et al. [15] suggested that VEGF could be an important growth factor for the onset of gingivitis and its progression to periodontitis.

\section{CONCLUSIONS}

On the basis of our findings, increased angiogenic activity with increased VEGF production was observed in endothelial cells in the vessel wall of the nicotine-administered group. Our study showed that cell degeneration, inflammation and changes in ligaments with disorders in vascular structure all prevent tooth to bind to alveolar part and periodontal gingiva. Increased amount of VEGF protein in endothelial cells induces angiogenesis. It is thought that the change of vessels location due to nicotine effect may promote endothelial cells to proliferation. Nicotine reduces MMP2 production, disrupts collagen synthesis and causes periodontitis. It is stated that nicotine increases periodontitis by disrupting periodontal membrane and prevents teeth to anchor in dental alveoli by disrupting epithelial structure.

\section{REFERENCES}

1. Alexopoulou AN, Multhaupt HAB, Couchman JR. Syndecans in wound healing, inflammation and vascular biology. Int J Biochem Cell Biol. 2007; 39(3): 505-528, doi: 10.1016/j.biocel.2006.10.014, indexed in Pubmed: 17097330.

2. Baniță M, Pisoschi C, Stănciulescu C, et al. Phenytoininduced gingival overgrowth-an immunohistochemical study of TGF- $\beta 1$ mediated pathogenic pathways. Farmacia. 2011; 59: 24-33.
3. Bartold PM, Narayanan AS. Molecular and cell biology of healthy and diseased periodontal tissues. Periodontol 2000. 2006; 40: 29-49, doi: 10.1111/j.16000757.2005.00140.x, indexed in Pubmed: 16398684.

4. Beklen A, Ainola M, Hukkanen M, et al. MMPs, IL-1, and TNF are regulated by IL-17 in periodontitis. J Dent Res. 2007; 86(4): 347-351, doi: 10.1177/154405910708600 409, indexed in Pubmed: 17384030.

5. Bergström J. Periodontitis and smoking: an evidencebased appraisal. J Evid Based Dent Pract. 2006; 6(1): 33-41, doi: 10.1016/j.jebdp.2005.12.018, indexed in Pubmed: 17138394.

6. Bildt MM, Bloemen M, Kuijpers-Jagtman AM, et al. Collagenolytic fragments and active gelatinase complexes in periodontitis. J Periodontol. 2008; 79(9): 1704-1711, doi: 10.1902/jop.2008.080021, indexed in Pubmed: 18771372.

7. Booth V, Young S, Cruchley A, et al. Vascular endothelial growth factor in human periodontal disease. J Periodontal Res. 1998; 33(8): 491-499, indexed in Pubmed: 9879523.

8. Bosco AF, Bonfante $S$, de Almeida JM, et al. A histologic and histometric assessment of the influence of nicotine on alveolar bone loss in rats. J Periodontol. 2007; 78(3): 527-532, doi: 10.1902/jop.2007.060149, indexed in Pubmed: 17335377.

9. Carty CS, Soloway PD, Kayastha S, et al. Nicotine and cotinine stimulate secretion of basic fibroblast growth factor and affect expression of matrix metalloproteinases in cultured human smooth muscle cells. J Vasc Surg. 1996; 24(6): 927-34; discussion 934, indexed in Pubmed: 8976346.

10. Cetinkaya BO, Keles GC, Ayas B, et al. The expression of vascular endothelial growth factor in a rat model at destruction and healing stages of periodontal disease. J Periodontol. 2007; 78(6): 1129-1135, doi: 10.1902/ jop.2007.060397, indexed in Pubmed: 17539728.

11. Chen D, Wang Qi, Ma ZW, et al. MMP-2, MMP-9 and TIMP2 gene polymorphisms in Chinese patients with generalized aggressive periodontitis. J Clin Periodontol. 2007; 34(5): 384-389, doi: 10.1111/j.1600-051X.2007.01071.x, indexed in Pubmed: 17448043.

12. D'Aiuto F, Parkar M, Andreou G, et al. Periodontitis and systemic inflammation: control of the local infection is associated with a reduction in serum inflammatory markers. J Dent Res. 2004; 83(2): 156-160, doi: 10.1177/1544059 10408300214 , indexed in Pubmed: 14742655.

13. Faruk ER, Deveci E, Kalkanli S, et al. The effects of nicotine on the incisive teeth and expression of vimentin in rats. Int J Morphol. 2013; 31(2): 516-519, doi: 10.4067/s071795022013000200026.

14. Giannobile WV. Host-response therapeutics for periodontal diseases. J Periodontol. 2008; 79(8 Suppl): 1592-1600, doi: 10.1902/jop.2008.080174, indexed in Pubmed: 18673015.

15. Giannobile WV, Al-Shammari KF, Sarment DP. Matrix molecules and growth factors as indicators of periodontal disease activity. Periodontol 2000. 2003; 31: 125-134, indexed in Pubmed: 12656999.

16. Graves DT, Fine D, Teng YTA, et al. The use of rodent models to investigate host-bacteria interactions related to periodontal diseases. J Clin Periodontol. 2008; 35(2): 89-105, doi: 10.1111/j.1600-051X.2007.01172.x, indexed in Pubmed: 18199146. 
17. Güneri $P$, Unlü $F$, Yeşilbek $B$, et al. Vascular endothelial growth factor in gingival tissues and crevicular fluids of diabetic and healthy periodontal patients. J Periodontol. 2004; 75(1): 91-97, doi: 10.1902/jop.2004.75.1.91, indexed in Pubmed: 15025220.

18. Haber J, Wattles J, Crowley M, et al. Evidence for cigarette smoking as a major risk factor for periodontitis. J Periodontol. 1993; 64(1): 16-23, doi: 10.1902/jop.1993.64.1.16, indexed in Pubmed: 8426285.

19. Henemyre CL, Scales DK, Hokett SD, et al. Nicotine stimulates osteoclast resorption in a porcine marrow cell model. J Periodontol. 2003; 74(10): 1440-1446, doi: 10.1902/ jop.2003.74.10.1440, indexed in Pubmed: 14653389.

20. Ingman T, Tervahartiala T, Ding Y, et al. Matrix metalloproteinases and their inhibitors in gingival crevicular fluid and saliva of periodontitis patients. J Clin Periodontol. 1996; 23(12): 1127-1132, indexed in Pubmed: 8997658.

21. Johnson GK, Hill M. Cigarette smoking and the periodontal patient. J Periodontol. 2004; 75(2): 196-209, doi: 10.1902/ jop.2004.75.2.196, indexed in Pubmed: 15068107.

22. Johnson RB, Serio FG, Dai X. Vascular endothelial growth factors and progression of periodontal diseases. J Periodontol. 1999; 70(8): 848-852, doi: 10.1902/ jop.1999.70.8.848, indexed in Pubmed: 10476891.

23. Just $M$, Ribera $M$, Monsó $E$, et al. Effect of smoking on skin elastic fibres: morphometric and immunohistochemical analysis. Br J Dermatol. 2007; 156(1): 85-91, doi: 10.1111/j.1365-2133.2006.07575.x, indexed in Pubmed: 17199572.

24. Keles GC, Cetinkaya BO, Eroglu C, et al. Vascular endothelial growth factor expression levels of gingiva in gingivitis and periodontitis patients with/without diabetes mellitus. Inflamm Res. 2010; 59(7): 543-549, doi: 10.1007/s00011010-0158-8, indexed in Pubmed: 20127137.

25. Kotsovilis S, Tseleni-Balafouta S, Charonis A, et al. Syndecan-1 immunohistochemical expression in gingival tissues of chronic periodontitis patients correlated with various putative factors. J Periodontal Res. 2010; 45(4): 520-531, doi: 10.1111/j.1600-0765.2009.01267.x, indexed in Pubmed: 20412418

26. Kubota T, Itagaki M, Hoshino $\mathrm{C}$, et al. Altered gene expression levels of matrix metalloproteinases and their inhibitors in periodontitis-affected gingival tissue. J Periodontol. 2008; 79(1): 166-173, doi: 10.1902/jop.2008.070159, indexed in Pubmed: 18166107.

27. Kumar MS, Vamsi G, Sripriya R, et al. Expression of matrix metalloproteinases (MMP-8 and -9) in chronic periodontitis patients with and without diabetes mellitus. J Periodontol. 2006; 77(11): 1803-1808, doi: 10.1902/ /jop.2006.050293, indexed in Pubmed: 17076603.

28. Lee W, Aitken S, Sodek J, et al. Evidence of a direct relationship between neutrophil collagenase activity and periodontal tissue destruction in vivo: role of active enzyme in human periodontitis. J Periodontal Res. 1995; 30(1): 23-33, indexed in Pubmed: 7722844.

29. Levin L, Levine J. Cigarette smoking and radiographic alveolar bone height and density. N Y State Dent J. 2010; 76(6): 31-35, indexed in Pubmed: 21226404
30. Liu YF, Wu LA, Wang J, et al. Micro-computerized tomography analysis of alveolar bone loss in ligature- and nicotine-induced experimental periodontitis in rats. J Periodontal Res. 2010; 45(6): 714-719, doi: 10.1111/j.16000765.2010.01290.x, indexed in Pubmed: 20572916.

31. Lucarini G, Zizzi A, Aspriello SD, et al. Involvement of vascular endothelial growth factor, CD44 and CD133 in periodontal disease and diabetes: an immunohistochemical study. J Clin Periodontol. 2009; 36(1): 3-10, doi: 10.1111/j.1600-051X.2008.01338.x, indexed in Pubmed: 19017033.

32. Miyagawa A, Chiba M, Hayashi $H$, et al. Compressive force induces VEGF production in periodontal tissues. J Dent Res. 2009; 88(8): 752-756, doi: 10.1177/0022034509341637, indexed in Pubmed: 19734464.

33. Nagase H, Woessner J. Matrix Metalloproteinases. J Biol Chem. 1999; 274(31): 21491-21494, doi: 10.1074/jbc.274.31.21491.

34. Nordskog B, Blixt A, Morgan W, et al. Matrix-Degrading and Pro-Inflammatory Changes in Human Vascular Endothelial Cells Exposed to Cigarette Smoke Condensate. Cardiovasc Toxicol. 2003; 3(2): 101-118, doi: 10.1385/ct:3:2:101.

35. Pisoschi C, Banita M, Stanciulescu C. Fusaru, AM, Gheorghita $\mathrm{M}$. Influence of some mediators of extracellular matrix remodeling on angiogenesis in diabetic gingival overgrowth. Proceedings of the 34th FEBS Congress, FEBS Journal. 2009; 27: 217.

36. Shapiro S. Matrix metalloproteinase degradation of extracellular matrix: biological consequences. Curr Opin Cell Biol. 1998; 10(5): 602-608, doi: 10.1016/s09550674(98)80035-5.

37. Taubman MA, Kawai T, Han X. The new concept of periodontal disease pathogenesis requires new and novel therapeutic strategies. J Clin Periodontol. 2007; 34(5): 367-369, doi: 10.1111/j.1600-051X.2007.01065.x, indexed in Pubmed: 17448041.

38. Tipton DA, Dabbous MK. Effects of nicotine on proliferation and extracellular matrix production of human gingival fibroblasts in vitro. J Periodontol. 1995; 66(12): 1056-1064, doi: 10.1902/jop.1995.66.12.1056, indexed in Pubmed: 8683418.

39. Thomson WM, Broadbent JM, Welch D, et al. Cigarette smoking and periodontal disease among 32-year-olds: a prospective study of a representative birth cohort. J Clin Periodontol. 2007; 34(10): 828-834, doi: 10.1111/j.1600051X.2007.01131.x, indexed in Pubmed: 17850601.

40. Tomar SL, Asma S. Smoking-attributable periodontitis in the United States: findings from NHANES III. National Health and Nutrition Examination Survey. J Periodontol. 2000; 71(5): 743-751, doi: 10.1902/jop.2000.71.5.743, indexed in Pubmed: 10872955.

41. Yoshizaki T, Sato H, Furukawa M. Recent advances in the regulation of matrix metalloproteinase 2 activation: from basic research to clinical implication (Review). Oncol Rep. 2002; 9(3): 607-611, indexed in Pubmed: 11956636.

42. Yuhara S, Kasagi $S$, Inoue $A$, et al. Effects of nicotine on cultured cells suggest that it can influence the formation and resorption of bone. Eur J Pharmacol. 1999; 383(3): 387-393, indexed in Pubmed: 10594333. 